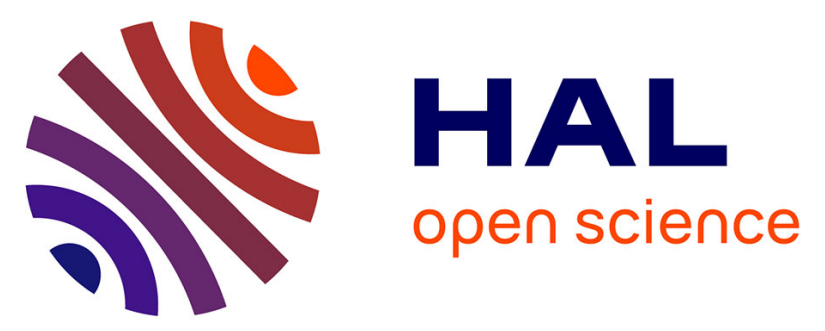

\title{
Mathematical models of radiation action on living cells: From the target theory to the modern approaches. A historical and critical review
}

Larry Bodgi, Aurélien Canet, Laurent Pujo-Menjouet, Annick Lesne, Jean-Marc Victor, Nicolas Foray

\section{To cite this version:}

Larry Bodgi, Aurélien Canet, Laurent Pujo-Menjouet, Annick Lesne, Jean-Marc Victor, et al.. Mathematical models of radiation action on living cells: From the target theory to the modern approaches. A historical and critical review. Journal of Theoretical Biology, 2016, 394, pp.93 - 101. 10.1016/j.jtbi.2016.01.018. hal-01382777

\section{HAL Id: hal-01382777 \\ https://inria.hal.science/hal-01382777}

Submitted on 7 Dec 2016

HAL is a multi-disciplinary open access archive for the deposit and dissemination of scientific research documents, whether they are published or not. The documents may come from teaching and research institutions in France or abroad, or from public or private research centers.
L'archive ouverte pluridisciplinaire HAL, est destinée au dépôt et à la diffusion de documents scientifiques de niveau recherche, publiés ou non, émanant des établissements d'enseignement et de recherche français ou étrangers, des laboratoires publics ou privés. 


\section{Mathematical models of radiation action on living cells: from the}

target theory to the modern approaches. An historical and critical review

Larry Bodgi $^{1,2}$, Aurélien Canet ${ }^{1,3}$, Laurent Pujo-Menjouet ${ }^{3}$, Annick Lesne ${ }^{4}$, Jean-Marc Victor ${ }^{4}$ and Nicolas Foray ${ }^{1 *}$

${ }^{1}$ Institut National de la Santé et de la Recherche Médicale (INSERM), UMR1052, Radiobiology Group, Cancer Research Centre of Lyon, 69008, Lyon, France; ${ }^{2}$ Université Saint-Joseph, Faculté des sciences, 1107-2050, Beyrouth, Liban; ${ }^{3}$ Institut Camille Jordan, Université Claude Bernard Lyon 1, 69622, Villeurbanne, France; ${ }^{4}$ Centre National de la Recherche Scientifique (CNRS), UMR7600, Laboratoire de physique théorique de la matière condensée, 75252, Paris, France ;

Keywords : DSB repair; ionising radiations.

${ }^{\#}$ Author for correspondence: Dr. Nicolas Foray

INSERM UMR 1052, Centre de Recherche en Cancérologie de Lyon, Groupe de Radiobiologie, 28 Rue Laennec 69008 LYON FRANCE 


\begin{abstract}
Cell survival is conventionally defined as the capability of irradiated cells to produce colonies. It is quantified by the clonogenic assays that consist in determining the number of colonies resulting from a known number of cells. Since the discovery of X-rays, several mathematical models were proposed to describe the survival curves, notably from the target theory; The Linear-Quadratic (LQ) model, which is to date the most frequently used model in radiobiology and radiotherapy, dominates all the other models by its robustness and simplicity. Its usefulness is particularly important because the ratio of the values of the $\alpha$ and $\beta$ adjustable parameters on which it is based predict the occurrence of post-irradiation tissular reactions. However, the biological interpretation of these parameters is still unknown.

Throughout this review, we proposed to revisit and discuss historically, mathematically and biologically, the different models of the radiation action by providing clues for resolving the enigma of the LQ model.
\end{abstract}




\section{Introduction}

Cellular radiosensitivity was conventionally defined as the capability of irradiated cells to produce daughter cells (i.e. colonies). It is quantified by the clonogenic assays that consist in determining the number of colonies resulting from a given number of cells irradiated at a given dose. Generally plotted on a semi-log scale, the survival fraction obeys a decreasing exponential-like law with or without shoulder (Puck and Marcus, 1956). Several mathematical models were proposed to describe cell survival curves (Curtis, 1991). Interestingly, the hypotheses on which they are based reflect the conceptual advances in our understanding of the radiation response (Fig. 1):

- between the 20's and the 50's, the most extensively used cell survival models were directly derived from the target theory, such as the single target single hit, n-targets single-hit and $n$-hits $n$-targets models, including the so-called $\left(n, \mathrm{D}_{0}\right)$ model (Elkind and Whitmore, 1967).

- between the 50's and the 80 's, the $\left(n, \mathrm{D}_{0}\right)$ model was intensely used. However, the evidence that the initial slope of the survival curve was not nil has significantly decreased its interest. In the early 80 's, the linear-quadratic (LQ) model was preferred because of its very good fitting qualities, but the empiric nature of its $\alpha$ and $\beta$ parameters encouraged the authors to develop other models (Chadwick and Leenhouts, 1973).

- between the 80's and the 90's, more sophisticated models were proposed by introducing the notion of DNA damage repair but without leading to formulas simpler than the LQ model, nor providing a clear mechanistic explanation to the radiationinduced phenomena. It is notably the case of the Repair-MisRepair (RMR) (Tobias, 1985), the Lethal-Potential Lethal (LPL) (Curtis, 1986), and the saturated repair models (Goodhead, 1985). 
- since the 90's, while there is a lower infatuation towards the biostatistical models describing cell survival, radiobiologists started focusing on the description of the DNA damage repair kinetics linked to cell survival (Bodgi et al., 2013; Cucinotta et al., 2000; Foray et al., 2005; Gastaldo et al., 2008; Iliakis, 1991; Neumaier et al., 2012; Radivoyevitch et al., 1998; Sontag, 1997).

\section{The target theory and its major related cell survival models}

\subsection{The genesis of the target theory}

Funded by physicists, the target theory is based on two major principles:

- “1) radiation is considered to be random projectiles;

- 2) the components of the cell are considered as the targets to be bombarded by these projectiles" (Summers, 2011).

The target theory has been firstly applied by J.A. Crowther in 1924 through an analysis of data from an experiment on chick embryo cells exposed to soft X-rays that was performed by Strangeways and Oakley in 1923 (Crowther, 1924; Strangeways and Oakley, 1923). In this case, the sensitive targets were hypothesized to be mitosis cells (Crowther, 1924). In 1929, F. Holweck $^{1}$ and A. Lacassagne obtained survival curves from bacillus irradiated by UV, X-rays or alpha-particles (Holweck and Lacassagne, 1929 ; Holweck and Lacassagne, 1930). Marie Curie herself analyzed the data and all these authors proposed the basis of the so-called quantum radiobiology: "to destroy a bacillus is it necessary that its sensitive zone absorbs a

\footnotetext{
${ }^{1}$ Born in 1889, Fernand Holweck became assistant of Marie Curie in 1912. During the first World War, he helped P. Langevin in his works for detecting submarines by ultrasonic waves. Holweck developed a number of instruments like the most powerful vacuum-producing, a gravimetric pendulum, the first x-ray tube with successive stages of acceleration. Through his collaboration with Dr. A. Lacassagne, Holweck rediscovered, independently of previous work by Crowther, the quantic interpretation of the biological action of radiation on microorganisms. During the second World War, he was actively engaged in defense work but was arrested, tortured and murdered by the Gestapo on December 14th, 1941, in a Paris prison.
} 
minimal number s of quantas" (Curie, 1929). From all these pioneer applications of the target theory, three important comments concerning hits and targets must be done:

- 1) The probability density function (pdf) that was systematically applied to describe hits inside sensitive cellular targets was a Poisson law.

- 2) The actual nature of the sensitive cellular targets was not consensual: they can be sub-populations of certain cells or some part of the nucleus.

- 3) The survival of irradiated cell was considered as the only result of the absence of any hit on sensitive cells.

\subsection{The basic ballistic models}

2.2.1 The single-target single hit-model. It is the simplest application of the target theory. Directly derived from the hypotheses of Crowther and Marie Curie, it was highlighted by Douglas Lea ${ }^{2}$ at the end of 50's through its book “Actions of radiation action on living cells" (Lea, 1946). The single-target single hit-model dominates with both its simplicity and robustness all the approaches leading to cell survival. It is based on the hypothesis that a single impact in the sensitive part is enough to kill the cell. By considering the Poisson probability to hit $\mathrm{k}$ times a target:

$$
P(k)=\frac{m^{k}}{k !} e^{-m}
$$

The probability of no impact is therefore:

2 Douglas E. Lea (MA, PhD) was born in 1910 in Great Britain. During his career, he worked as a physicist at England's Strangeways Laboratory and as a reader in the Department of Radiobiology in the Department of Radiotherapeutics at Cambridge University. The majority of his work dealt with the effects of radiation on cells. Lea died in an accident in Cambridge, England, on June 16, 1947. 


$$
P(0)=e^{-m}
$$

We consider that $\mathrm{m}$ is proportional to the dose. Hence, if the survival is directly linked to the no impact probability we have:

$$
S(D)=e^{-a D} \text { or } S(D)=e^{-\frac{D}{D_{0}}}
$$

Where $\mathrm{D}_{0}$ is the mean lethal dose for which the mean number of lethal events per cell is equal to 1 . At $\mathrm{D}_{0}$, the fraction of cell survival is equal to $1 / \mathrm{e}$ or $37 \%(0.367879$ exactly) (Fig.2A).

2.2.2 The n-target single-hit model. This model was based on the hypothesis that one cell contains $\mathrm{n}$ identical targets. The inactivation of one target was considered to be a sublethal event, and the accumulation of these sublethal events will lead to cell death, which will occur once the $\mathrm{n}$ targets are hit. Hence, by considering the probabilities of the single-target singlehit model, the probability that one target is hit once obeys the Poisson pdf:

$$
p(1)=1-e^{-\frac{D}{D_{0}}}
$$

Therefore, the probability that $\mathrm{n}$ targets from the same cell are hit once is:

$$
p(n)=\left(1-e^{-\frac{D}{D_{0}}}\right)^{n}
$$

Thus, the survival fraction is given by the following formula:

$$
S(D)=1-\left(1-e^{-\frac{D}{D_{0}}}\right)^{n}
$$

The curve is described by the final slope $\mathrm{D}_{0}$ and a parameter that defines the width of the shoulder $\left(n\right.$ or $D_{q}$ ). The $n$-target single-hit model was therefore called the $\left(n, D_{0}\right)$ model (Elkind and Whitmore, 1967) (Fig. 2B).

2.2.3 Criticisms of the ballistic models. The great majority of cell survival curves obtained from mammalian cells do not obey both the single-target single hit and the (n,Do) models : to the notable exception of the hyper-radiosensitive cells that show exponential curves, all the 
other human cases are characterized by a shoulder and an initial part that is not nil (fig. $2 \mathrm{~A}$ and 2B). These last observations are in clear discrepancy with the description showed by the (n,Do) model. To overcome this problem, the two-component model was proposed by considering an additional single-target component, which allows the initial slope value to be fixed at a given dose $\mathrm{D}_{1}$. The resulting survival equation becomes:

$$
S(D)=e^{\frac{-D}{D_{1}}}\left(1-\left(1-e^{-D\left(\frac{1}{D_{0}}-\frac{1}{D_{1}}\right)}\right)^{n}\right)
$$

However, although the two-component model is able to predict in an acceptable way the cell survival at low doses, it still has the default that the decrease in cell survival for a dose between 0 and $\mathrm{D}_{\mathrm{q}}$ occurs linearly, which has not been demonstrated experimentally (Joiner and Van Der Kogle, 2009). Even though the use of a multi-target instead of a single-target component would be able to solve this drawback, the general survival formula would become too complicated, and therefore not really useful to compare survival curves and explain the radiation response mechanisms (Steel, 1993).

To date, despite all the efforts in introducing some modifications and in addition to the problems evoked above, the models directly derived from the target theory appear to be unable to describe the phenomenon of hypersensitivity to low-dose that is characterized by a $\mathrm{V}$-shaped part in the 1-400 mGy range and that is in clear discrepancy with the target theory (Marples and Collis, 2008) (Fig.2D)

\subsection{The linear-quadratic model and its variants}

2.3.1 The linear-quadratic model. In 1972, Kellerer and Rossi introduced the linear-quadratic (LQ) model in which a lethal event is supposed to be caused by one hit due to one particle track (the linear component $\alpha \mathrm{D}$ ) or to two particle tracks (the quadratic component $\beta \mathrm{D}^{2}$ ) 
(Kellerer and Rossi, 1972; Kellerer and Rossi, 1978). However, the probability that two particles tracks overlap is nil at biologically-relevant doses (Goodhead, 1989). In 1973, Chadwick and Leenhouts proposed that $\alpha \mathrm{D}$ reflects unrepairable (i.e. directly lethal) DNA double-strand-breaks (DSB) and $\beta \mathrm{D}^{2}$ reflects the combination of two sublethal DNA singlestrand breaks (SSB) (Chadwick and Leenhouts, 1973). Again, at biologically-relevant doses, IR-induced SSB are not close enough to produce DSB (Goodhead, 1989). To date, while the LQ model still generates numerous debates, inherent bio-molecular mechanisms remain misknown (Brenner and Herbert, 1997; Brenner et al., 2012). Despite of its empirical nature, the LQ model is considered as the best fitting model to describe survival (fig. 2C) (Fertil et al., 1994), and of great interest in radiation oncology through the link existing between the $\alpha / \beta$ ratio and the nature of radiotherapy-induced tissue (early or late) reactions (Barendsen, 1982; Brenner et al., 2012; Dale, 1985; Williams et al., 1985).

$$
S(D)=e^{-\alpha D-\beta D^{2}}
$$

2.3.2. The LQ model variants to describe the high-dose effects. While the LQ model provides good fit for survival curves at biologically relevant doses, the accuracy of the survival description was found to be limited for higher or repeated doses. Douglas and Fowler therefore proposed the three-lambda model that consisted in a superimposition of three exponential terms (Douglas and Fowler, 1976). In their model the survival equation was:

$$
S(D)=e^{-\lambda_{3}\left(1-e^{\lambda_{1} D}\left(1-\left(1-e^{-\left(\lambda_{2}-\lambda_{1}\right) D}\right)^{2}\right)\right)}
$$

The linear-quadratic-cubic model was also proposed to describe the response to higher doses by adding another cubic term to the polynomial function of the LQ model (Joiner, 1993; Tobias, 1985): 


$$
S(D)=e^{-\alpha D-\beta D^{2}-\gamma D^{3}}
$$

2.3.3 Criticisms of the LQ models and its variants. While the usefulness of the three-lambda and the linear-quadratic-cubic models is quite relative since very high single doses are not really relevant for radiobiologists, the paradox of the LQ model is that it provides an actual robustness for fitting data while it remains an empirical model (Fertil et al., 1994).

\section{The models based on the sublesions hypothesis and their variants}

\subsection{The repair-misrepair model}

Proposed by Tobias in 1985, the repair-misrepair (RMR) model describes the evolution of the $\mathrm{U}(\mathrm{t})$ function, that reflects the mean number of lesions before any repair activation (Tobias, 1985). The yield of induction of these lesions, $U_{0}$, was considered proportional to the dose $D$ :

$$
U_{0}=\delta D
$$

The repair states $\mathrm{R}$ are defined as being the resultant transformation of the $\mathrm{U}$ lesions after the repair process. The author considered that the evolution of the $\mathrm{U}$ lesions can be described by the following differential equation:

$$
\frac{d U}{d t}=-\lambda U(t)-k U^{2}(t)
$$

With $\lambda$ the linear self-repair coefficient, considered to be the good repair pathway, and $\kappa$ the coefficient for cooperative repair, involving the interaction of pairs of $U$ lesions, that the author considered to be the misrepair. By integrating the equation we have:

$$
U(t)=\frac{U_{0} e^{-\lambda t}}{1+\frac{U_{0}\left(1-e^{-\lambda t}\right)}{\frac{\lambda}{k}}}
$$

Two R-states were therefore defined: $\mathrm{R}_{\mathrm{L}}(\mathrm{t})$, the total number of self-repairs, which are the 
non-lethal lesions, and $\mathrm{R}_{\mathrm{Q}}(\mathrm{t})$, the total number of quadratic misrepairs, which are considered to be the lethal lesions:

$$
\begin{aligned}
& \mathrm{R}_{\mathrm{L}}=\int_{0}^{\mathrm{t}} \lambda \mathrm{U}(\mathrm{t}) \mathrm{dt} \\
& \mathrm{R}_{\mathrm{Q}}=\int_{0}^{\mathrm{t}} \mathrm{k} \mathrm{U}^{2}(\mathrm{t}) \mathrm{dt}
\end{aligned}
$$

By considering that no new lesion is created during the repair process, we have:

$$
\mathrm{U}_{0}=\mathrm{U}(\mathrm{t})+\mathrm{R}_{\mathrm{L}}(\mathrm{t})+\mathrm{R}_{\mathrm{Q}}(\mathrm{t})
$$

when $\mathrm{t} \rightarrow \infty$, equation (13) becomes:

$$
\mathrm{R}_{\mathrm{Q}}(\mathrm{t} \rightarrow \infty)=\mathrm{U}_{0}-\mathrm{R}_{\mathrm{L}}(\mathrm{t} \rightarrow \infty)
$$

If we consider the repair ratio $\varepsilon=\lambda / \kappa$, and by applying Poisson pdf, the survival equation becomes:

$$
\mathrm{S}=\mathrm{e}^{-\mathrm{R}_{\mathrm{Q}}(\mathrm{t} \rightarrow \infty)}=\mathrm{e}^{-\mathrm{U}_{0}}\left[1+\frac{\mathrm{U}_{0}}{\varepsilon}\right]^{\varepsilon}
$$

By considering that the linear repair is not a perfect process, the author introduced the parameter $\phi$ that defines the probability that self-repair steps are all perfect eurepairs. Furthermore, by considering that the repair time is limited at a time $\mathrm{T}$, the survival equation becomes (fig 2E):

$$
\mathrm{S}_{\phi=} \mathrm{e}^{-\mathrm{U}_{0}}\left[1+\frac{\phi \mathrm{TU}_{0}}{\varepsilon}\right]^{\varepsilon}
$$




\subsection{The lethal-potentially lethal model}

Curtis developed in 1986 the Lethal-Potentially Lethal model (LPL) model that takes the repair process into account (Curtis, 1986). He proposed a classification of the radio-induced lesions: lesions "that are unrepairable and are therefore lethal", and "potentially lethal lesions for which the repair process is activated". Thus, two differential equations are necessary to describe the repair kinetics:

$$
\begin{gathered}
\frac{d n_{P L}}{d t}=-\varepsilon_{P L} n_{P L}(t)-\varepsilon_{2 P L} n_{P L}(t)^{2} \\
\frac{d n_{L}}{d t}=\varepsilon_{2 P L} n_{P L}(t)^{2}
\end{gathered}
$$

with $\mathrm{n}_{\mathrm{PL}}$ the number of potentially lethal lesions, $\mathrm{n}_{\mathrm{L}}$ the number of lethal lesions, $\varepsilon_{\mathrm{PL}}$ the constant per unit of time repair rate and $\varepsilon_{2 \mathrm{PL}}$ the constant per unit of time rate of interaction between 2 potentially lethal lesions, a process that Curtis called the binary misrepair (fig.2F). The solutions to equations (16) are:

$$
\begin{gathered}
\mathrm{n}_{\mathrm{PL}}(\mathrm{t})=\frac{\mathrm{N}_{\mathrm{PL}} \mathrm{e}^{-\epsilon_{\mathrm{PL}} \mathrm{t}_{\mathrm{r}}}}{\left[1+\left(\mathrm{N}_{\mathrm{PL}} / \epsilon\right)\left(1-\mathrm{e}^{-\epsilon_{\mathrm{PL}} \mathrm{t}_{\mathrm{r}}}\right)\right]} \\
\mathrm{n}_{\mathrm{L}}(\mathrm{t})=\mathrm{N}_{\mathrm{L}}+\frac{\mathrm{N}_{\mathrm{PL}}\left(1+\frac{\mathrm{N}_{\mathrm{PL}}}{\epsilon}\right)\left(1-\mathrm{e}^{-\epsilon_{\mathrm{PL}} \mathrm{t}_{\mathrm{r}}}\right)}{\left[1+\left(\mathrm{N}_{\mathrm{PL}} / \epsilon\right)\left(1-\mathrm{e}^{-\epsilon_{\mathrm{PL}} \mathrm{t}_{\mathrm{r}}}\right)\right]}-\epsilon \ln \left[1+\left(\mathrm{N}_{\mathrm{PL}} / \epsilon\right)\left(1-\mathrm{e}^{-\epsilon_{\mathrm{PL}} \mathrm{t}_{\mathrm{r}}}\right)\right]
\end{gathered}
$$

where $\mathrm{N}_{\mathrm{PL}}=\mathrm{n}_{\mathrm{PL}}(\mathrm{T}), \mathrm{N}_{\mathrm{L}}=\mathrm{n}_{\mathrm{L}}(\mathrm{T}), \epsilon=\epsilon_{\mathrm{PL} /} \epsilon_{2 \mathrm{PL}}, \mathrm{T}$ is the irradiation duration and $\mathrm{t}_{\mathrm{r}} \mathrm{is}$ the available repair time

In order to predict the survival at a time $\mathrm{t}=\mathrm{T}+\mathrm{t}_{\mathrm{r}}$, time after which the repair process is ineffective, Curtis considered that the total number of lesions per cell is the sum of lethal and potentially lethal lesions. In other words, he hypothesizes that after a certain time, all the potentially lethal lesions become lethal. Hence, the total number of lesions $n_{\text {tot }}$ is

$$
\mathrm{n}_{\text {tot }}\left(\mathrm{T}+\mathrm{t}_{\mathrm{r}}\right)=\mathrm{n}_{\mathrm{L}}\left(\mathrm{T}+\mathrm{t}_{\mathrm{r}}\right)+\mathrm{n}_{\mathrm{PL}}\left(\mathrm{T}+\mathrm{t}_{\mathrm{r}}\right)
$$

The survival equation becomes: 


$$
\mathrm{S}=\mathrm{e}^{-\mathrm{n}_{\text {tot }}\left(\mathrm{T}+\mathrm{t}_{\mathrm{r}}\right)}=\mathrm{e}^{-\mathrm{N}_{\text {tot }}}\left[1+\mathrm{N}_{\mathrm{PL}} / \varepsilon\left(1-\mathrm{e}^{-\varepsilon_{\mathrm{PL}} \mathrm{t}_{\mathrm{r}}}\right)\right]^{\varepsilon}
$$

with $\mathrm{N}_{\mathrm{TOT}}=\mathrm{N}_{\mathrm{L}}+\mathrm{N}_{\mathrm{PL}}$ and $\varepsilon=\varepsilon_{\mathrm{PL}} / \varepsilon_{2 \mathrm{PL}}$ (fig. 6)

\subsection{The saturable repair model}

In 1985, Dudley T. Goodhead proposed a new model, the saturable repair model that was based on the hypothesis that the efficiency of the repair system decreases with dose, and that this decrease is caused by the saturation of the repair kinetics (Goodhead, 1985). He therefore considered the following repair rate for the induced lesions:

$$
\frac{d n}{d t}=-k c n
$$

Where $\mathrm{n}$ is the number of unrepaired lesions, $\mathrm{c}$ the number of repair molecules or enzymes and $\mathrm{k}$ is a proportionality coefficient. By considering that $d c=d n$ and that $\mathrm{T}$ is the time available for repair, the residual number of lesions after repair becomes:

$$
n_{T}=\frac{n_{0}-c_{0}}{1-\frac{c_{0}}{n_{0}} e^{k T\left(c_{0}-n_{0}\right)}}
$$

Hence the survival equation:

$$
S(D)=e^{-\frac{n_{0}-c_{0}}{1-\frac{c_{0}}{n_{0}} e^{k T\left(c_{0}-n_{0}\right)}}}
$$

By considering the repair process as saturable, this model does not require the notion of sublesions like the lethal and potentially lethal/sublethal ones (fig. 2G). It was therefore presented as an alternative to the RMR and LPL models (Goodhead, 1985).

\subsection{Criticisms of the sublesion and saturable models}

The notion of the lethal and potentially lethal lesions is directly derived from the attempts to interpret the LQ model. Particularly, as evoked above, the quadratic component was systematically explained by a duality of tracks, single-strand breaks or cooperative lesions. However, the actual nature of the sublesions still remains undefined. Besides, this idea is 
related to the direct/indirect effect hypothesis that suggests that some damage are directly induced by the impact of the physical particles and some other by the chemical radicals produced by such impact. In fact, it has been clearly shown that DNA damage are induced simulataneously and that radicals attack was not a 2-time-phase phenomenon (Foray et al., 1996a; Foray et al., 1998; Kysela et al., 1993). Furthermore, both RMR and LPL models considered the misrepaired lesions as lethal lesions, which is in clear discrepancy with cytogenetics and new advances in radiobiology. Indeed, it is more accepted that misrepaired lesions are more likely involved in genomic instability and cell transformation rather than cell death and radiosensitivity (Jeggo and Lobrich, 2007).

Unlike the models that are directly derived from the target theory, the sublesions (LPL and RMR) models are based on the notion of DNA damage repair. Although it is suggested that these lesions might DSB, they are not formally identified as the damage of interest. Furthermore, their repair rate per unit of time described in the LPL and RMR models was hypothesized to be constant. Such an assumption is in discrepancy with the multiphasic shape of the DSB repair kinetics which would reflect the existence of a continuous spectrum of DSB of differing reparabilities rather than a limited number of DSB subcategories (Foray et al., 1996a; Foray et al., 2005; Foray et al., 1998). An experimental proof of the continuous nature of DSB repair kinetics is given by the shape of the DSB repair curves obtained after a given dose followed by a period of time (some min to some hours): in these conditions, DSB repair curves are never mono- or bi-phasic but systematically continuously decreasing (Foray et al., 1996a; Foray et al., 2005; Foray et al., 1998) which contradicts the hypothesis of the LPL and RMR models.

With regard to the saturable repair model, the major assumption is the saturation of the repair enzymes pool. Up to date, such an hypothesis was not verified. While some tens of DSB are induced per Gy, the average yield of each protein ranges from $10^{4}$ to $10^{8}$ molecules, it appears 
unlikely that the repair enzymes pool can be saturated. Some radiosensitive syndromes are not necessarily caused by a decreased of DSB repair kinetics, inasmuch as these syndromes are caused by mutations of cytoplasmic proteins like Huntington's disease, neurofibromatosis or Usher's syndrome (Deschavanne and Fertil, 1996; Ferlazzo et al., 2014). Furthermore, that the DSB repair rate is not necessarily dependent of dose rate and the irradiation at low dose-rate for long times (some days) does lead to the absence of repair (Foray et al., 1996b).

Altogether, like the models derived from the target theory, the RMR, LPL and saturable repair models do not solve two important radiobiological questions, at least:

- $\quad$ the very documented hypersensitivity to low doses (Joiner et al., 2001)

- the fact that some radiosensitive syndromes are not necessarily associated with DNA damage repair defect (Deschavanne and Fertil, 1996; Ferlazzo et al., 2014).

\section{Modern approaches}

\subsection{The target theory must be reconsidered to explain radiosensitivity of mammalians}

The models deriving from the target theory must consider that:

- (1) physical hits obey a Poisson pdf;

- (2) cell survival is due to the absence of hits in the sensitive areas of the irradiated cells;

- (3) since all the number of hits is proportional to the dose and since all the hits are lethal, survival is a simple exponential function of the dose.

Such hypotheses are relevant for micro-organisms but are not for mammalian cells. Indeed, by considering that the relevance of the above hypothesis (1) and that about 40 DSB are produced per human cell per Gy, the probability of an absence of impact is lower than $10^{-17}$. Conversely, different DSB assays like pulsed-field gel electrophoresis and $\gamma \mathrm{H} 2 \mathrm{AX}$ immunofluorescence show that the yield of induced DSB per mammalian cell does not obey a 
Poisson pdf but rather a Gauss pdf (Noda et al., 2012; Rothkamm and Lobrich, 2003). Hence, the hypotheses (2) and (3) deriving from the target theory must therefore be reconsidered for mammalian cells: cells likely survive because all their DNA damage are repaired rather than because cells are not targeted by IR (Lea, 1946; Sutherland, 2006) (fig. 3). Furthermore, it must be reminded that, in addition to the 40 DSB induced per cells, X- and gamma-rays also induce simultaneously 1000 SSB and 10000 base damage per Gy (these numbers of are divided by more than 100 in the case of the bacteria or yeasts): it is therefore surprising that from the pioneer works of Crowther and Marie Curie (i.e. the 1930's), only few radiobiologists (D.E. Lea was one of them (Lea, 1946)) discussed about the relevance of the target theory for other species than micro-organisms.

\subsection{The moderate radiosensitivity must be considered when testing survival models}

The great majority of mammalian cells show a non-negligible initial slope and a shoulder when cell survival is plotted against dose, which is in clear discrepancy with target theory and especially (n,Do) model (Malaise et al., 1987). The only cell lines that can show exponential survival curve are the most hyper-radiosensitive ones such as those mutated for ATM, LIG4 or DNA-PK proteins (Iliakis, 1991; Joubert et al., 2008). In the frame of the LQ model, the maximal shoulder is obtained by the cells that show a maximal $\beta$ LQ parameter, which corresponds to a moderate radiosensitivity (average $\alpha$ ). The cell lines showing the most moderate radiosensitivity are therefore a good tool to exclude a number of irrelevant cell survival models. Interestingly, as evoked above, some genetic syndromes associated with moderate sensitivity are not caused by mutations of proteins directly involved in DSB repair but are rather cytoplasmic and have no function in DNA damage repair. This is notably the case of the Huntington's disease, neurofibromatosis or Usher's syndrome (Deschavanne and Fertil, 1996; Ferlazzo et al., 2014). In complete contradiction with the target theory, such 
syndromes provide clues that cytoplasm proteins may impact on radiation response and that considering both nuclear targets and DNA repair is not sufficient to explain all the range of human radiosensitivity.

\subsection{The radiation-induced nucleo-shuttling of ATM: a solution to some enigmas?}

In the frame of our collection of skin biopsies from radiotherapy patients showing adverse tissue reactions, we have accumulated from 2003 some hundreds fibroblast cell lines whose radiation response has been investigated with the major DSB repair biomarkers (Granzotto et al., submitted). Interestingly, it appeared that the phosphorylated forms of the ATM protein translocate from cytoplasm to nucleus in response to radiation. For the patients showing moderate radiosensitivity, such radiation-induced nucleo-shuttling of ATM was delayed, probably because the ATM proteins are sequestrated by mutated proteins in cytoplasm (Ferlazzo et al., 2014). Since ATM protein is known to phosphorylate the $\gamma \mathrm{H} 2 \mathrm{AX}$ variant histone that is considered as the recognition step of DSB by the preponderant DSB repair pathway in humans, the non-homologous end-joining (NHEJ), two categories of lethal DSB can be defined: 1) the recognized by non-repaired DSB; 2) the non-recognized therefore nonrepaired DSB. We have shown that these DSB categories called $\alpha$-type and $\beta$-type, increase with dose or with the square of the dose, respectively (Bodgi and Foray, submitted). Such findings support therefore that the LQ model, that provides the best cell survival data fits, provides also the best relevance with molecular mechanisms in response to radiation. It is also noteworthy that the theory of the nucleo-shuttling of ATM and the LQ model are the most compatible with the hypersensitivity to low-dose phenomenon (Bodgi and Foray, 2014; Colin et al., 2011; Joiner et al., 2001; Thomas et al., 2013) (Bodgi and Foray, submitted). 


\section{Conclusions}

To date, it appears to date that most of the biostatistical models of cell survival are not relevant to describe the radiation response of mammalians. However, the re-analysis of the princeps papers provides strong evidence that the general theory and pdf on which these models are based were built from micro-organisms data whose size and characteristics are clearly different from the mammalians case. It is therefore not surprising that the LQ model, based on a very permissive $2^{\text {nd }}$ degree polynomial function provides the best cell survival data fits. Nevertheless, the biological interpretation of the LQ parameters remained unsolved since the 1970's. Today, by taking into account the radiation-induced nucleo-shuttling of ATM that is very far from the target theory, coherent explanations of the descriptive power of the LQ model and of some misknown radiobiological phenomena can be proposed. 


\section{References}

Barendsen, G. W., 1982. Dose fractionation, dose rate and iso-effect relationships for normal tissue responses. Int J Radiat Oncol Biol Phys 8, 1981-97.

Bodgi, L., Foray, N., 2014. The nucleo-shuttling of the ATM protein as a basis for a novel theory of radiation response: resolution of the linear-quadratic model. submitted.

Bodgi, L., Granzotto, A., Devic, C., Vogin, G., Lesne, A., Bottollier-Depois, J. F., Victor, J. M., Maalouf, M., Fares, G., Foray, N., 2013. A single formula to describe radiationinduced protein relocalization: towards a mathematical definition of individual radiosensitivity. J Theor Biol 333, 135-45.

Brenner, D. J., Herbert, D. E., 1997. The use of the linear-quadratic model in clinical radiation oncology can be defended on the basis of empirical evidence and theoretical argument. Med Phys 24, 1245-8.

Brenner, D. J., Sachs, R. K., Peters, L. J., Withers, H. R., Hall, E. J., 2012. We forget at our peril the lessons built into the alpha/beta model. Int J Radiat Oncol Biol Phys 82, 1312-4, doi:10.1016/j.ijrobp.2011.12.045.

Chadwick, K. H., Leenhouts, H. P., 1973. A molecular theory of cell survival. Physics Medicine Biology 13, 78-87.

Colin, C., Granzotto, A., Devic, C., Viau, M., Maalouf, M., Vogin, G., Joubert, A., Thomas, C., Foray, N., 2011. MRE11 and H2AX biomarkers in the response to low-dose exposure: Balance between individual susceptibility to radiosensitivity and to genomic instability. Internation Journal of Low Radiation in press.

Crowther, J. A., 1924. Some considerations relative to the action of X-rays on tissue cells. Proceedings of the Royal Society London B96, 207-211.

Cucinotta, F. A., Nikjoo, H., O'Neill, P., Goodhead, D. T., 2000. Kinetics of DSB rejoining and formation of simple chromosome exchange aberrations. Int $\mathrm{J}$ Radiat Biol 76, 1463-74.

Curie, M., 1929. Sur l'étude des courbes de probabilité relatives à l'action des rayons X sur les bacilles Comptes-Rendus de l'Ac\&démie des Sciences 188, 202-204.

Curtis, S. B., 1986. Lethal and potentially lethal lesions induced by radiation--a unified repair model. Radiat Res 106, 252-70.

Curtis, S. B., 1991. Mechanistic models. Basic Life Sci 58, 367-82; discussion 382-6.

Dale, R. G., 1985. The application of the linear-quadratic dose-effect equation to fractionated and protracted radiotherapy. Br J Radiol 58, 515-28.

Deschavanne, P. J., Fertil, B., 1996. A review of human cell radiosensitivity in vitro. Int J Radiat Oncol Biol Phys 34, 251-66.

Douglas, B. G., Fowler, J. F., 1976. The effect of multiple small doses of x rays on skin reactions in the mouse and a basic interpretation. Radiat Res 66, 401-26.

Elkind, M. M., Whitmore, G. F., 1967. The radiobiology of cultured mammalian cells. Gordon and Breach, New York.

Ferlazzo, M. L., Sonzogni, L., Granzotto, A., Bodgi, L., Lartin, O., Devic, C., Vogin, G., Pereira, S., Foray, N., 2014. Mutations of the Huntington's Disease Protein Impact on the ATM-Dependent Signaling and Repair Pathways of the Radiation-Induced DNA Double-Strand Breaks: Corrective Effect of Statins and Bisphosphonates. Mol Neurobiol 49, 1200-1211, doi:10.1007/s12035-013-8591-7. 
Fertil, B., Reydellet, I., Deschavanne, P. J., 1994. A benchmark of cell survival models using survival curves for human cells after completion of repair of potentially lethal damage. Radiat Res 138, 61-9.

Foray, N., Badie, C., Alsbeih, G., Fertil, B., Malaise, E. P., 1996a. A new model describing the curves for repair of both DNA double-strand breaks and chromosome damage. Radiat Res 146, 53-60.

Foray, N., Charvet, A. M., Duchemin, D., Favaudon, V., Lavalette, D., 2005. The repair rate of radiation-induced DNA damage: a stochastic interpretation based on the gamma function. J Theor Biol 236, 448-58.

Foray, N., Fertil, B., Alsbeih, M. G., Badie, C., Chavaudra, N., Iliakis, G., Malaise, E. P., 1996b. Dose-rate effect on radiation-induced DNA double-strand breaks in the human fibroblast HF19 cell line. Int J Radiat Biol 69, 241-9.

Foray, N., Monroco, C., Marples, B., Hendry, J. H., Fertil, B., Goodhead, D. T., Arlett, C. F., Malaise, E. P., 1998. Repair of radiation-induced DNA double-strand breaks in human fibroblasts is consistent with a continuous spectrum of repair probability. Int J Radiat Biol 74, 551-60.

Gastaldo, J., Viau, M., Bouchot, M., Joubert, A., Charvet, A. M., Foray, N., 2008. Induction and repair rate of DNA damage: a unified model for describing effects of external and internal irradiation and contamination with heavy metals. J Theor Biol 251, 68-81.

Goodhead, D. T., 1985. Saturable repair models of radiation action in mammalian cells. Radiat Res Suppl 8, S58-67.

Goodhead, D. T., 1989. The initial physical damage produced by ionizing radiations. Int J Radiat Biol 56, 623-34.

Holweck, F., Lacassagne, A., 1929 Compt. rend. Acad, 188,197;.

Holweck, F., Lacassagne, A., 1930. Compt. rend. Soc. biol., 103, 60;.

Iliakis, G., 1991. The role of DNA double strand breaks in ionizing radiation-induced killing of eukaryotic cells. Bioessays 13, 641-8.

Jeggo, P. A., Lobrich, M., 2007. DNA double-strand breaks: their cellular and clinical impact? Oncogene 26, 7717-9.

Joiner, M. C., 1993. Models of radiation cell killing. In: Steel, G. G., (Ed.), Basic clinical radiobiology. Edward Arnold, London.

Joiner, M. C., Van Der Kogle, A., 2009. Basic clinical radiobiology.

Joiner, M. C., Marples, B., Lambin, P., Short, S. C., Turesson, I., 2001. Low-dose hypersensitivity: current status and possible mechanisms. Int J Radiat Oncol Biol Phys 49, 379-89.

Joubert, A., Gamo, K., Bencokova, Z., Gastaldo, J., Rénier, W., Chavaudra, N., Favaudon, V., Arlett, C., Foray, N., 2008. DNA double-strand break repair defects in syndromes associated with acute radiation response: at least two different assays to predict intrinsic radiosensitivity? International Journal of Radiation Biology 84, 1-19.

Kellerer, A. M., Rossi, H. H., 1972. The theory of dual radiation action. Current Topics in Radiation Research 8, 85-158.

Kellerer, A. M., Rossi, H. H., 1978. A generalized formulation of dual radiation action. Radiation Research 75, 471-488.

Kysela, B. P., Michael, B. D., Arrand, J. E., 1993. Relative contributions of levels of initial DNA damage and repair of double strand breaks to the ionizing radiation-sensitive phenotype of the Chinese hamster cell mutant, XR-V15B. Part I. X-rays. Int J Radiat Biol 63, 609-16.

Lea, D. E., 1946. Actions of radiations on living cells. Cambridge University Press, London. 
Malaise, E. P., Fertil, B., Deschavanne, P. J., Chavaudra, N., Brock, W. A., 1987. Initial slope of radiation survival curves is characteristic of the origin of primary and established cultures of human tumor cells and fibroblasts. Radiat Res 111, 319-33.

Marples, B., Collis, S. J., 2008. Low-dose hyper-radiosensitivity: past, present, and future. Int J Radiat Oncol Biol Phys 70, 1310-8.

Neumaier, T., Swenson, J., Pham, C., Polyzos, A., Lo, A. T., Yang, P., Dyball, J., Asaithamby, A., Chen, D. J., Bissell, M. J., Thalhammer, S., Costes, S. V., 2012. Evidence for formation of DNA repair centers and dose-response nonlinearity in human cells. Proc Natl Acad Sci U S A 109, 443-8.

Noda, A., Hirai, Y., Hamasaki, K., Mitani, H., Nakamura, N., Kodama, Y., 2012. Unrepairable DNA double-strand breaks that are generated by ionising radiation determine the fate of normal human cells. J Cell Sci 125, 5280-7, doi:10.1242/jcs. 101006.

Puck, T. T., Marcus, P. I., 1956. Action of x-rays on mammalian cells. J Exp Med 103, 65366.

Radivoyevitch, T., Hoel, D. G., Hahnfeldt, P. J., Rydberg, B., Sachs, R. K., 1998. Recent data obtained by pulsed-field gel electrophoresis suggest two types of double-strand breaks. Radiat Res 149, 52-8.

Rothkamm, K., Lobrich, M., 2003. Evidence for a lack of DNA double-strand break repair in human cells exposed to very low x-ray doses. Proc Natl Acad Sci U S A 100, 5057-62.

Sontag, W., 1997. A discrete cell survival model including repair after high dose-rate of ionizing radiation. Int J Radiat Biol 71, 129-44.

Steel, G., 1993. Basic Clinical Radiobiology. Arnold Publishers.

Strangeways, T. S. P., Oakley, H. E. H., 1923. The immediate changes observed in tissue cells after exposure to soft X-rays while growing in vitro. Proceedings of the Royal Society London B 95, 373-381.

Summers, W. C., 2011. Physics and genes : From Einstein to Delbrück. In: Sloan, P. R., Fogel, B., Eds.), Creating a Physical Biology: The Three-Man Paper and Early Molecular Biology. The University of Chicago Press, Chicago, USA, pp. 39-68.

Sutherland, J. C., 2006. Repair dependent radiation survival : a stochastic model with Euler gamma function solutions. Physics Medicine Biology 51, 4883-4901.

Thomas, C., Martin, J., Devic, C., Diserbo, M., Thariat, J., Foray, N., 2013. Impact of doserate on the low-dose hyper-radiosensitivity and induced radioresistance (HRS/IRR) response. International Journal of Radiation Biology 89, 813-822.

Tobias, C. A., 1985. The repair-misrepair model in radiobiology: comparison to other models. Radiat Res Suppl 8, S77-95.

Williams, M. V., Denekamp, J., Fowler, J. F., 1985. A review of alpha/beta ratios for experimental tumors: implications for clinical studies of altered fractionation. Int $\mathbf{J}$ Radiat Oncol Biol Phys 11, 87-96. 


\section{Figure legends:}

Figure 1 : Historical synopsis related to the cell survival models and their variants

Figure 2 : Summary of the major cellular models describing cell survival curves with the corresponding mathematical formulas linking clonogenic cell survival and radiation dose

Figure 3 : Schematic illustration of the influence of the target size on the radiobiological endpoints.

Figure 4 : Schematic illustration of our new model of the ATM nucleo-shuttling 


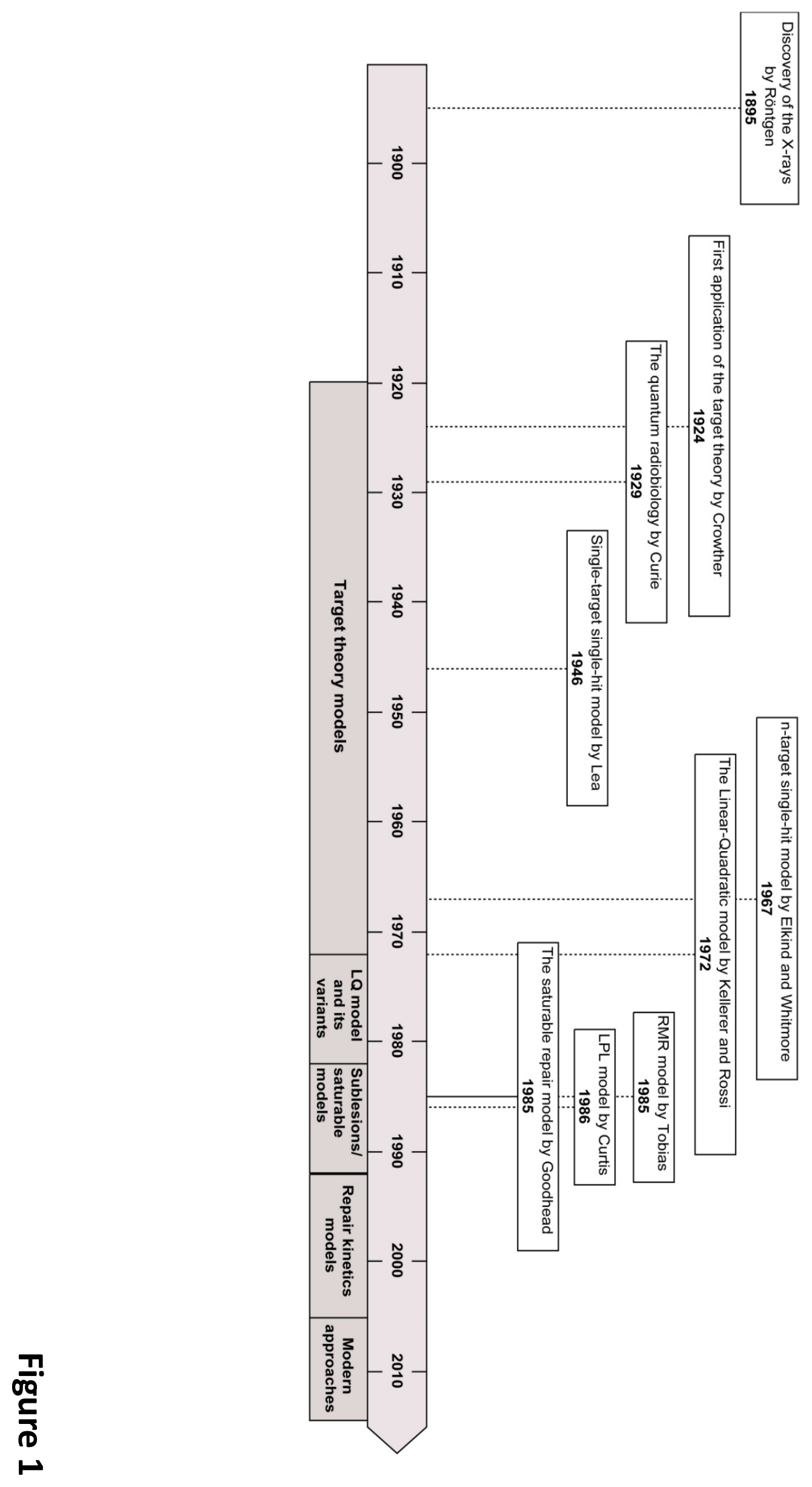



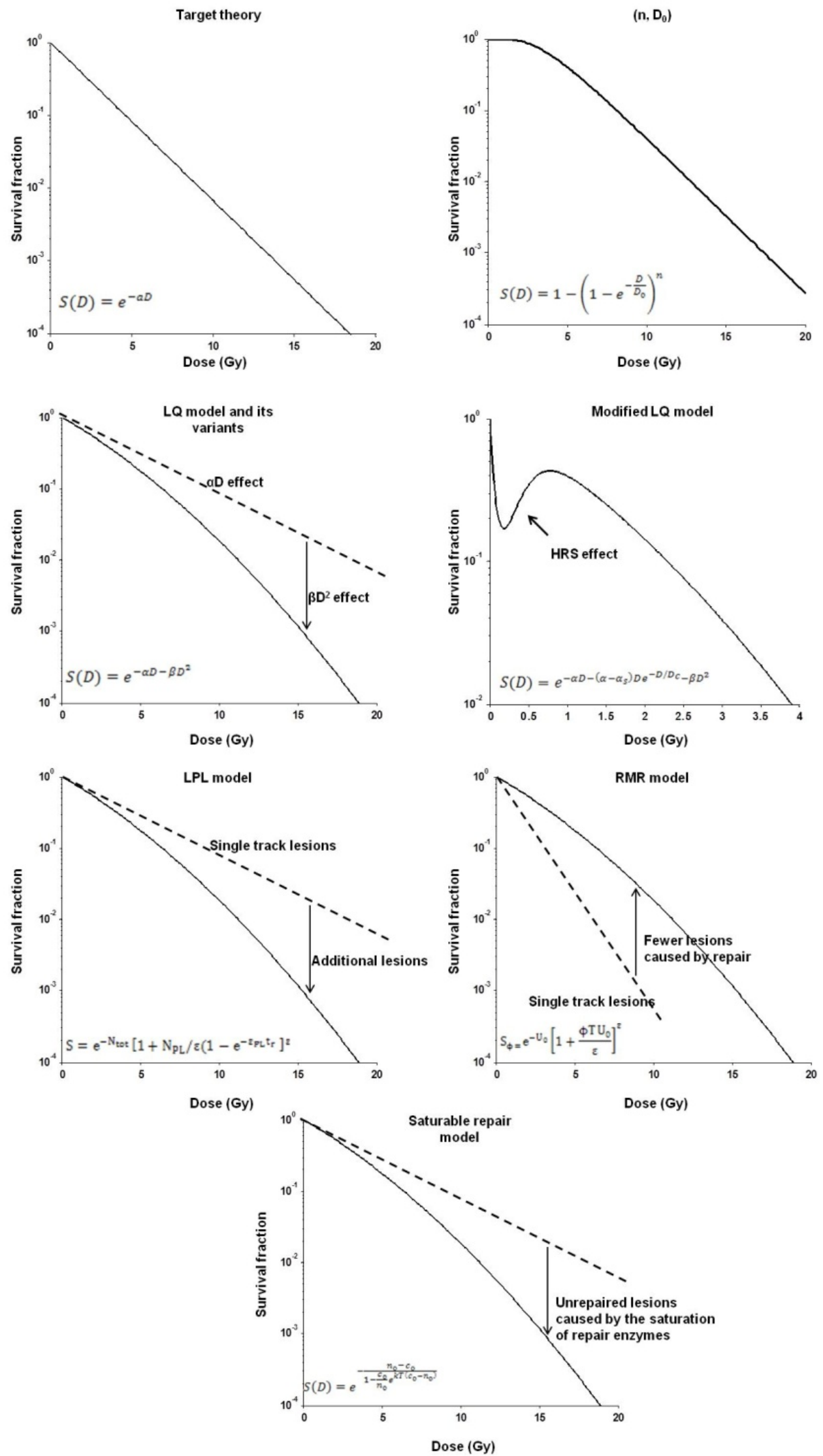

Figure 2 
Micro-organisms

Difference between species

Size of nuclei

Hit, DNA damage, repair and cell survival

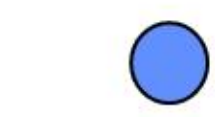

Diameter: $\sim 1 \mu \mathrm{m}$

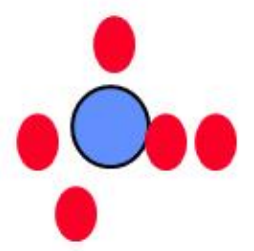

Survives if no hit. Rather radioresistant
Human cells

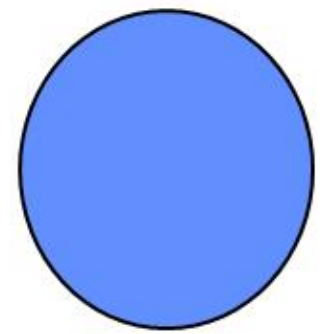

Diameter: $\sim 10 \mu \mathrm{m}$

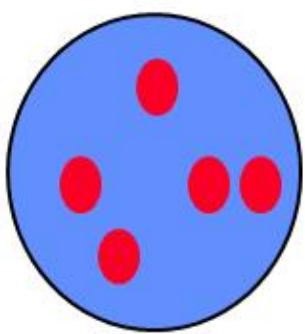

Survives if all the damage are repaired.

Rather radiosensitive

\section{POISSON}

GAUSS

per cell

POISSON

Physical hit

Probability law

POISSON

Hit probability

Number of DNA

damage vs dose

Proportionnal

Proportionnal

Cell survival vs dose

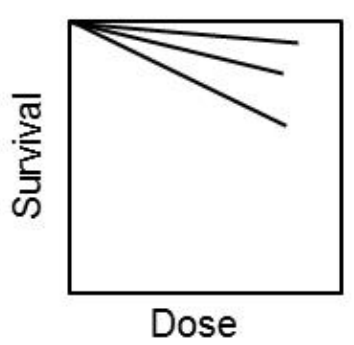

